\title{
Mechanical, hygric and thermal properties of innovative renovation renders
}

\author{
E. Vejmelková ${ }^{1}$, M. Keppert ${ }^{1}$, P. Máca ${ }^{2} \&$ R. Černý ${ }^{1}$ \\ ${ }^{1}$ Department of Materials Engineering and Chemistry, \\ Faculty of Civil Engineering, Czech Technical University in Prague, \\ Czech Republic \\ ${ }^{2}$ Experimental Center, Faculty of Civil Engineering, \\ Czech Technical University in Prague, Czech Republic
}

\begin{abstract}
Basic physical properties, mechanical, hygric, and thermal properties of three lime plasters containing metakaolin as pozzolana admixture and provided with different amounts of hydrophobizing additive are investigated in the paper. As the designed plasters are intended for renovation of historical buildings, their properties are compared with two commercial renovation renders commonly used in the building practice. Experimental results show that using the hydrophobizing additive in the amount of $1 \%$ of the mass of binder is the most prospective solution. The porosity of this plaster meets the basic WTA requirement of $40 \%$. Its mechanical properties are comparable with the commercial plasters. The liquid water transport properties are favourable, the water vapor transport is somewhat slower than optimal but still acceptable, the thermal properties are satisfactory. Taking into consideration that this level of properties is achieved without using any kind of cement which is in accordance with the present effort of conservators to use materials with traditional composition, one may expect that this plaster can find successful application in reconstruction of historical buildings in the future.
\end{abstract}

Keywords: lime plasters, metakaolin, hydrophobizing additive, properties.

\section{Introduction}

Mortar is one of the oldest artificially prepared construction materials. It was frequently used in the era of Ancient Rome as well as in other parts of the world. 
The ancient mortar was composed of quicklime and pozzolana filler such as tuff, volcanic ash, spongilite or alternatively ground burnt clay. The chemical reaction of the pozzolanic materials with lime produced hydrated calcium silicates and calcium aluminates. These chemical compounds significantly enhanced mortar durability and environmental resistance. However, in the 16th century the production of lime was industrialized and the pozzolanic admixtures were no longer added to the mortar mixture. Both hydraulic lime and pure lime was produced. The time showed that mortars made solely from pure lime were not preserved and their durability resistance proved to be unsatisfactory. Since the end of 19th century, cement began to substitute hydraulic lime usage in construction industry. As a compound of plasters it was used since the 1920s.

The present effort of conservators is to use materials with traditional composition for conservation of historical buildings. It is also required that the plasters are applied by original construction methods. Therefore, it is not acceptable to use cement in plasters in romanesque, gothic, renaissance and baroque buildings repairs. Binda et al. [1] discussed the choice of mortar for the reconstruction of the Cathedral of Noto. They recommended a hydraulic lime for mortar; if a good hydraulic lime was not available the use of hydrated lime and pozzolana was acceptable. Arioglu and Acun [2] presented an analysis of the restoration of traditional lime mortars and plasters. Their flow diagram showed a recommended experimental method for the process of design of repair mortars and plasters. They recommended application of ready-to-use repair mortars.

Metakaolin is a pozzolana that appears to greatly enhance properties of lime mixtures [3-5]. In Central Europe its use is also acceptable from a conservator's point of view. Kaolinite has been used for centuries on the Czech territory.

This paper presents basic physical, mechanical, hygric and thermal properties of three lime plasters containing metakaolin as pozzolana admixture and provided with different amounts of hydrophobizing additive. As the presented plasters are intended for application to renovation of historical buildings, their properties are compared with two commercial renovation renders.

\section{Materials}

The composition of studied renders is shown in Table 1. All three plasters contained the same amount of pozzolana admixture - metakaolin (in the ratio 1: 3 to lime). They differed in the amount of hydrophobizing additives used for their preparation - the particular mixes are denoted as RP 1, RP 2 and RP 3. The percentage in brackets shown in Table 1 is the ratio between the hydrophobizing additive and binder (lime and metakaolin together). The chemical composition of the used metakaolin is shown in Table 2, the specific surface of metakaolin was $13.1 \mathrm{~m}^{2} / \mathrm{g}$. Metakaolin was produced by "České lupkové závody Inc., Nové Strašecí" (CZ), lime in the kiln Čertovy schody (CZ). The other two tested plasters were commercial renovation renders denoted as CRP 1 and CRP 2. Their exact composition was not known. 
Table 1: The composition of studied plasters.

\begin{tabular}{|c|c|c|c|c|c|}
\hline & $\begin{array}{c}\text { Lime } \\
{[\mathrm{kg}]}\end{array}$ & $\begin{array}{c}\text { Metakaolin } \\
{[\mathrm{kg}]}\end{array}$ & $\begin{array}{c}\text { Hydrophobizing } \\
\text { additive } \\
{[\mathrm{kg}]}\end{array}$ & $\begin{array}{c}\text { Natural quartz and } \\
\text { basalt sand 0 to } 4 \mathrm{~mm} \\
{[\mathrm{~kg}]}\end{array}$ & w/b \\
\hline RP 1 & 1.875 & 0.625 & - & 7.5 & 0.27 \\
\hline RP 2 & 1.875 & 0.625 & $0.025(1 \%)$ & 7.5 & 0.27 \\
\hline RP 3 & 1.875 & 0.625 & $0.375(15 \%)$ & 7.5 & 0.27 \\
\hline CRP 1 & \multicolumn{6}{|l}{} & 0.23 \\
\hline CRP 2 & \multicolumn{6}{|l}{} & 0.17 \\
\hline
\end{tabular}

Table 2: $\quad$ Chemical composition of metakaolin (mass \%).

\begin{tabular}{|l|l|}
\hline \multirow{2}{*}{ Component } & \multicolumn{1}{|c|}{ Amount } \\
\cline { 2 - 2 } & \multicolumn{1}{|c|}{$[\%]$} \\
\hline $\mathrm{SiO}_{2}$ & 58.70 \\
\hline $\mathrm{Al}_{2} \mathrm{O}_{3}$ & 38.50 \\
\hline $\mathrm{Fe}_{2} \mathrm{O}_{3}$ & 0.72 \\
\hline $\mathrm{CaO}$ & 0.20 \\
\hline $\mathrm{MgO}$ & 0.38 \\
\hline $\mathrm{K}_{2} \mathrm{O}$ & 0.85 \\
\hline $\mathrm{TiO}_{2}$ & 0.50 \\
\hline
\end{tabular}

\section{Experimental methods}

\subsection{Basic physical properties}

The bulk density, matrix density and open porosity were measured using the water vacuum saturation method [6]. Each sample was dried in a drier to remove majority of the physically bound water. After that the samples were placed into the desiccator with deaired water. During three hours air was evacuated with vacuum pump from the desiccator. The specimen was then kept under water not less than 24 hours.

Characterization of pore structure was performed by mercury intrusion porosimetry (MIP). The experiments were carried out using the instruments PASCAL 140 and 440 (Thermo Scientific). The range of applied pressure corresponds to pore radius from $3 \mathrm{~nm}$ to $100 \mu \mathrm{m}$. 


\subsection{Mechanical properties}

The flexural strength was measured in bending on prisms with dimensions of $40 \times 40 \times 160 \mathrm{~mm}$ at the age of 28 days. The experimental work was performed according to ČSN EN 1015-11 [7], as standard three-point bending test using the MTS QTEST 100 testing machine. The span length between the supports was $100 \mathrm{~mm}$. Each specimen was placed on its side with respect to its position as molded on the supports of the testing device. The loading rate was $0.15 \mathrm{~mm} / \mathrm{min}$. Portions of the mortar prisms tested in flexure were used for the determination of compressive strength as described in ČSN EN 1015-11 [7], after 28 days of standard curing.

\subsection{Water vapor transport properties}

The dry cup method was employed in the measurements of water vapor transport parameters [6]. The water vapor diffusion coefficient $D\left[\mathrm{~m}^{2} \mathrm{~s}^{-1}\right]$ and water vapor diffusion resistance factor $\mu$ [-] were determined. The measurement was done on the samples with the dimensions of $50 \times 50 \times 20 \mathrm{~mm}$.

\subsection{Water transport properties}

The water absorption coefficient $A\left[\mathrm{~kg} \mathrm{~m}^{-2} \mathrm{~s}^{-1 / 2}\right]$ and apparent moisture diffusivity $\kappa\left[\mathrm{m}^{2} \mathrm{~s}^{-1}\right]$ were measured using a water sorptivity experiment $[8,9]$. The measurement was done on the samples with the dimensions of $50 \times 50 \times 20 \mathrm{~mm}$.

\subsection{Thermal properties}

Thermal conductivity $\lambda\left[\mathrm{W} \mathrm{m}^{-1} \mathrm{~K}^{-1}\right]$ and specific heat capacity $c\left[\mathrm{~J} \mathrm{~kg}^{-1} \mathrm{~K}^{-1}\right]$ were measured using the commercial device ISOMET 2104 (Applied Precision, Ltd.). The measurement is based on analysis of the temperature response of the analyzed material to heat flow impulses. The heat flow is induced by electrical heating using a resistor heater having a direct thermal contact with the surface of the sample. The measurement was done on the samples with the dimensions of $70 \times 70 \times 70 \mathrm{~mm}$.

\section{Experimental results}

\subsection{Basic physical properties}

Table 3 shows that the addition of hydrophobizing agent led to slight decrease of bulk density and matrix density and to certain increase of open porosity (up to 2\%). The commercial plaster CRP 1 achieved lower bulk density, higher matrix density and substantially higher open porosity than RP1-RP3. CRP 2 had comparable properties to RP3. 
Table 3: $\quad$ Basic physical properties of studied plasters.

\begin{tabular}{|c|c|c|c|}
\hline \multirow{2}{*}{ Material } & $\boldsymbol{\rho}$ & $\rho_{\mathbf{m a t}}$ & $\psi$ \\
\cline { 2 - 4 } & {$\left[\mathbf{k g ~ m}^{-\mathbf{3}}\right]$} & {$\left[\mathbf{k g ~ m}^{-\mathbf{3}}\right]$} & {$[\mathbf{\%}]$} \\
\hline RP 1 & 1584 & 2574 & 38.5 \\
\hline RP 2 & 1534 & 2554 & 39.9 \\
\hline RP 3 & 1454 & 2434 & 40.3 \\
\hline CRP 1 & 1384 & 2609 & 47.3 \\
\hline CRP 2 & 1479 & 2539 & 41.8 \\
\hline
\end{tabular}

Incremental porosity curves of all studied plasters are presented in Figure 1. The MIP experiment performed with RP 1-RP 3 revealed that the used hydrophobizing agent did not change the pore size distribution shape. Only minor porosity increase was observed between RP 1 and RP 2. The highest dosage of hydrophobizing agent (RP 3) did not cause any further increase of porosity; here the MIP data agreed with basic properties (Table 3 ). The pore size distribution of commercial plaster CRP 2 was very similar to those of prepared plasters RP. The only different material was found to be CRP 1; its porosity was significantly higher compared to the others. The explanation provided by MIP was that pore distribution of CRP 1 had completely different character. There was not observed the sharp peak at $1 \mu \mathrm{m}$ but the pore system consisted of wide range of pores ranging from 0.01 to $5 \mu \mathrm{m}$.



Figure 1: The pore size distribution of renovation plasters. 


\subsection{Mechanical properties}

The influence of hydrophobizing additive on compressive and bending strength is shown in Figure 2. The highest value of strength achieved reference material RP 1 without the usage of hydrophobic additive while the lowest strengths exhibited RP 3 with highest content of hydrophobizing agent (15\%). Both commercial renders CRP 1 and CRP 2 were characterized by similar values of compressive and bending strength as RP 2. Thus, the 1\% dosage of hydrophobizing agent seemed to be a suitable solution regarding the mechanical properties.

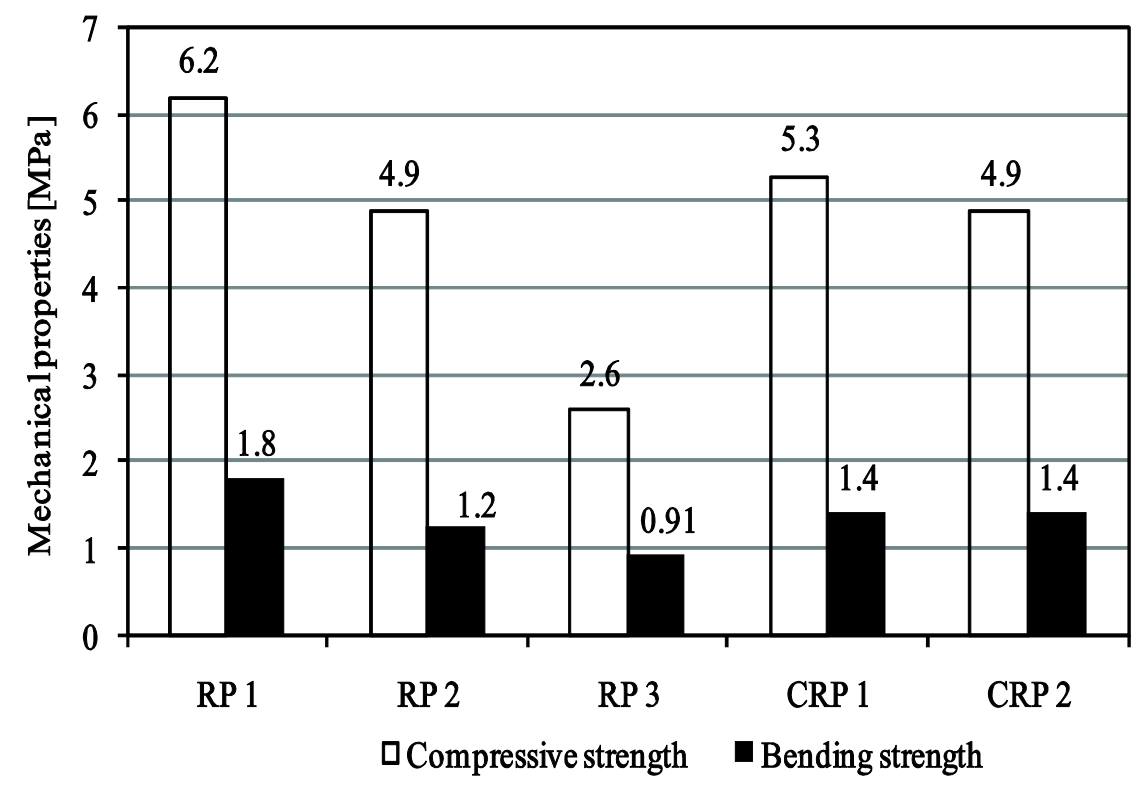

Figure 2: Mechanical properties of studied plasters.

\subsection{Water vapor transport properties}

Table 4 shows water vapor diffusion parameters of all investigated materials. The lowest ability of water vapor transport had reference material without hydrophobizing additive RP 1 . As follows from the experimental results, with the increase of open porosity and increase of the amount of hydrophobizing additive the ability of water vapor transport increased. The lowest values of water vapor diffusion resistance factor $\mu$ exhibited commercial plasters CRP1 and CRP2 (up to 4 times lower compared to RP 1). The high ability of water vapor transport is for renovation plasters one of crucial factors because it makes possible fast water vapor removal from both the plaster and the underlying structure. From that point of view the decrease of $\mu$ with increasing dosage of hydrophobization agent was favorable. Although RP 2 and RP 3 had still higher $\mu$ than commercial plasters, the values around 40 were acceptable. 
Table 4: $\quad$ Water vapor properties of studied plasters.

\begin{tabular}{|c|c|c|c|}
\hline \multirow{2}{*}{ Material } & \multicolumn{3}{|c|}{$\mathbf{5 / 5 0 \%}$} \\
\cline { 2 - 4 } & $\delta$ & $\mathbf{D}$ & $\mu$ \\
\cline { 2 - 4 } & {$[\mathbf{s}]$} & {$\left[\mathbf{m}^{\mathbf{2}} \mathbf{s}^{-\mathbf{1}}\right]$} & {$[-]$} \\
\hline RP 1 & $3.56 \mathrm{E}-12$ & $4.90 \mathrm{E}-07$ & 51.16 \\
\hline RP 2 & $4.27 \mathrm{E}-12$ & $5.87 \mathrm{E}-07$ & 40.48 \\
\hline RP 3 & $4.73 \mathrm{E}-12$ & $6.50 \mathrm{E}-07$ & 35.40 \\
\hline CRP 1 & $1.44 \mathrm{E}-11$ & $1.98 \mathrm{E}-06$ & 12.60 \\
\hline CRP 2 & $7.23 \mathrm{E}-12$ & $9.93 \mathrm{E}-07$ & 23.32 \\
\hline
\end{tabular}

\subsection{Water transport properties}

The results of water sorptivity measurements are presented in Table 5. The lowest rate of liquid water transport was observed in highly hydrophobized plaster RP 3; the plaster without any hydrophobic additive (RP 1) had the highest sorptivity as it was expected. The commercial plaster CRP 2 exhibited the highest ability of water transport, even higher than the reference plaster RP without hydrophobizing additions. The other commercial material CRP 1 with the highest value of open porosity achieved higher value of water absorption coefficient $A$ than the designed plasters RP 2 and RP 3 with hydrophobizing additions but lower than for reference material RP 1 . The moisture diffusivities differed from each other by one order of magnitude, following the differences of sorptivities used for their calculation.

Table 5: $\quad$ Water transport properties of studied plasters.

\begin{tabular}{|c|c|c|}
\hline \multirow{2}{*}{ Material } & $\mathbf{A}$ & $\boldsymbol{\kappa}$ \\
\cline { 2 - 3 } & {$\left[\mathbf{k g ~ m}^{-\mathbf{2}} \mathbf{s}^{-\mathbf{1} / \mathbf{2}}\right]$} & {$\left[\mathbf{m}^{\mathbf{2}} \mathbf{s}^{-\mathbf{1}}\right]$} \\
\hline RP 1 & 0.0873 & $6.69 \mathrm{E}-08$ \\
\hline RP 2 & 0.0242 & $1.72 \mathrm{E}-08$ \\
\hline RP 3 & 0.0118 & $3.30 \mathrm{E}-09$ \\
\hline CRP 1 & 0.0728 & $2.41 \mathrm{E}-08$ \\
\hline CRP 2 & 0.145 & $1.18 \mathrm{E}-07$ \\
\hline
\end{tabular}

It should be noted that while fast water vapor transport is desirable for renovation plasters with liquid water transport quite an opposite is true. Faster liquid water transport generally means higher load of the structure due to rain water penetration. Therefore, both RP 2 and RP 3 were found more suitable for practical application than commercially produced plasters CRP 1 and CRP 2. Taking into account also the mechanical properties (Figure 2), RP 2 seems to be a reasonable compromise from the point of view of the desired achievement of good mechanical and water transport properties at the same time. 


\subsection{Thermal properties}

The measured thermal properties are shown in Table 6 . The thermal conductivity of investigated materials was in a reasonable qualitative agreement with the porosities presented in Table 3. The lowest thermal conductivity exhibited CRP 1 having the highest porosity, the highest RP 1 with lowest porosity. The specific heat capacity of CRP 2 was highest among the studied plasters, for RP 1, RP 2 and RP 3 it was lowest and almost identical; CRP 1 was in between. The explanation certainly lies in the differences in composition of the analyzed materials which, however, cannot be specified in more detail due to the lack of information on the commercial plasters. The thermal diffusivity values followed the differences in thermal conductivity and specific heat capacity described above.

Table 6: $\quad$ Thermal properties of studied plasters in dry state.

\begin{tabular}{|c|c|c|c|}
\hline Materials & $\lambda\left[\mathrm{Wm}^{-1} \mathrm{~K}^{-1}\right]$ & $\mathrm{c}\left[\mathrm{Jkg}^{-1} \mathrm{~K}^{-1}\right]$ & $\mathrm{a}\left[10^{-6} \mathrm{~m}^{2} \mathrm{~s}^{-1}\right]$ \\
\hline RP 1 & 0.499 & 902 & 0.346 \\
\hline RP 2 & 0.470 & 888 & 0.331 \\
\hline RP 3 & 0.413 & 898 & 0.358 \\
\hline CRP 1 & 0.366 & 1028 & 0.260 \\
\hline CRP 2 & 0.464 & 1479 & 0.315 \\
\hline
\end{tabular}

\section{Conclusions}

Experimental analysis of basic physical, mechanical, hygric and thermal properties of three lime plasters intended for application to renovation of historical buildings and containing metakaolin as pozzolana admixture and different amounts of hydrophobizing additive was presented in the paper. Obtained data were compared with the corresponding parameters of two commercial renders. Based on the obtained experimental results and the economical point the view one may conclude that the optimum dosing of hydrophobizing additive was $1 \%$ of the mass of binder which was used in the RP 2 plaster. The mechanical properties of this plaster were comparable with the commercial plasters. Its porosity was about $40 \%$ what was required value by WTA for renovation plasters. The liquid water transport was significantly slower, which was an advantage for a renovation plaster; only the water vapor transport was somewhat slower than in the commercial plasters but still acceptable. The thermal properties were satisfactory, as well. Taking into account that this level of properties was achieved without using any kind of cement (which is uncertain in commercial renovation plasters where an exact composition is given only rarely), it can be concluded that the RP 2 plaster can find successful application in reconstruction of historical buildings in the future. 


\section{Acknowledgement}

This research has been supported by the Czech Science Foundation, under grant No 103/09/0780.

\section{References}

[1] Binda, L., Baronio, G., Tiraboschi, C. \& Tedeschi, C., Experimental research for the choice of adequate materials for the reconstruction of the Cathedral of Noto. Construction and Building Materials, 17, pp. 629-639, 2003.

[2] Arioglu, N., \& Acun, S., A research about a method for restoration of traditional lime mortars and plasters: A staging system and approach. Building and Environment, 41, pp. 1223-1230, 2006.

[3] Cabrera, J. \& Rojas, M.S., Mechanism of hydration of the metakaolin-limewater system. Cement and Concrete Research, 31, pp. 177-187, 2001.

[4] Rojas, M.S. \& Cabrera, J., The effect of temperature on the hydration rate and stability of the hydration phases of metakaolin-lime-water systems. Cement and Concrete Research, 32, pp. 133-138, 2002.

[5] Vejmelková, E., Pernicová, R., Sovják, R. \& Černý, R., Properties of innovative renders on lime basis for the renovation of historical buildings. Structural Studies, Repairs and Maintenance of Heritage Architecture XI, ed. C. A. Brebbia, WIT Press: Southampton, pp. 221-229, 2009.

[6] Roels, S., Carmeliet, J., Hens, H., Adan, O., Brocken, H., Černý, R., Pavlík, Z., Hall, C., Kumaran, K., Pel, L. \& Plagge, R., Interlaboratory Comparison of Hygric Properties of Porous Building Materials. Journal of Thermal Envelope and Building Science, 27, pp. 307-325, 2004.

[7] ČSN EN 1015-11, Methods of test for mortar for masonry - Part 11: Determination of flexural and compressive strength of hardened mortar. Czech Standardization Institute: Prague, 2000.

[8] Kumaran, M.K., Moisture diffusivity of building materials from water absorption measurements. Journal of Thermal Envelope and Building Science, 22, pp. 349-355, 1999.

[9] Vejmelková, E., Pavlíková, M., Jerman, M. \& Černý, R. Free Water Intake as Means of Material Characterization. Journal of Building Physics, 33, pp. 29-44, 2009. 